\title{
The Antimicrobial Activity of Leaf Extracts of Myrtus communis
}

\author{
Besufekad SY, Mekdes M, Abebech M, Delesa D, Tekalign D, Demitu K and Birtukan B
}

Department of Biotechnology, College of Natural and Computational Science, Wolkite University, Ethiopia

\begin{abstract}
Myrtus communis is medicinal plant with the common name known as "Ades" in Ethiopia. Despite of its antimicrobial uses, there is limited study on antimicrobial activities of essential oil against pathogenic bacterial and fungi strains. The objective of the study is to investigate antibacterial and anti-fungal activity of Myrtus communis against pathogenic bacterial strains including; Escherichia coli, Pseudomonas aeruginosa, Salmonella typhi and Staphylococcus aureus; fungi strains including Fusarium oxysporium and Asparegillus niger. The antibacterial activity was performed in vitro using agar disc diffusion assay and diameter of zone of inhibition was measured. The experiment was prepared in completely randomized design (CRD) with three replication. Calculations of antibacterial and antifungal activity were determined by mean value and standard deviation. Among all the extracts of $n$-hexane and methanolic extracts showed maximum antibacterial activity against $E$. coli and Staphylococcus aureus strain with a zone of inhibition ranges from $5.67-5.5 \mathrm{~mm}$ and the least activity was observed in chloroform and methanol extract with zone of inhibition range from 1-2.2 mm against Staphylococcus aureus. The test results were compared with standard antibiotics Chloramphenicol. On the hand chloroform possessed higher antifungal activity on Fusarium oxysporium with zone of inhibition value of $15.16 \mathrm{~mm}$ and the least zone of inhibition obtained from Methanol with zone of inhibition value of $4.75 \mathrm{~mm}$. The minimum inhibitory concentration (MIC) was conduct only for n-hexane extract because of its higher inhibition value than other solvents. The MIC value ranges from $3.125 \mathrm{mg} / \mathrm{mL}$ to $12.5 \mathrm{mg} / \mathrm{mL}$. The results suggest that $\mathrm{n}$-hexane and methanolic extracts of Myrtus communiscan be used in the treatment of infection caused by E.coli and Staphylococcus aureus strains and chloroform extract also used in the treatment of infection caused by Fusarium oxysporium.
\end{abstract}

Keywords: Antimicrobial activity; Extract; Myrtus communis; Minimum inhibitory concentration; Zone of inhibition

\section{Introduction}

Ethno-medicine studies the traditional medical practice and is concerned with the cultural investigation of health, disease and illness addresses the healthcare seeking process and healing practices [1]. Myrtus communis is medicinal plant with the common name myrtle and belongs to the family Myrtaceae, described by Linnaeus in 1753 [2]. Myrtus communis (Myrtus C.), myrtle, is an aromatic evergreen shrub with strong antibacterial, anti-inflammatory, disinfectant drug, hypoglycemic agent, anti-hyperglycemic and antioxidant activities [3].

Traditional methods of healing have been beneficial in many countries with or without access to conventional allopathic medicine. In Ethiopia, traditional medicine is an integral part of the local culture and is a major public health system [4]. Volatile oil of Myrtus communis have been used for several purposes, where the leaves are used to treat hypertension, hemorrhoids, common colds, lower blood glucose, pass kidney stones, hair restorer and wound healer. A study demonstrated that the protective action of topical formulation of Eugenia caryophyllata and Myrtus communis essential oil may be useful for the treatment of skin diseases causing microorganisms [5].

Despite of its antimicrobial uses, there is limited study on antimicrobial activities of Myrtus communis essential oil against pathogenic bacterial and fungi strains. Hence, this study investigated antibacterial and anti-fungal activity of Myrtus communis against bacterial strains including; Escherichia coli, Pseudomonas aeruginosa, Salmonella typhi and Staphylococcus aureus; fungi strains including Fusarium oxysporium and Aspergillus niger. Screening of ethno botanical have been found to offer traditionally used folk medicine into modern drug formulation and gave information in importance of traditional medicine. Therefore, this study aims at evaluating the Myrtus communis leaves extracts against microbial characteristics of pathogenic to human in order to associate pertaining information in society.

\section{Materials and Method}

The fresh leaf sample of Myrtus communis was purchased from Woliso, Ethiopia during April, 2017. The sample was confirmed by botanist and brought to biotechnology laboratory of Wolkite University for extraction of essential oil and antimicrobial activity test. After extraction of essential oil it was further purified to remove the extracting solvent for antimicrobial activity test. The sample evaporated in an oven at $60^{\circ} \mathrm{C}$ for $2 \mathrm{~h}$ and powdered form obtained. Finally, the dry weight of each extract was measured using electronic balance. The stock solution about $100 \mathrm{mg} / \mathrm{mL}$ concentration was prepared, autoclaved, vortexed and kept at $4^{\circ} \mathrm{C}$ in refrigerator [6].

\section{Preparation of test organisms and sensitivity test}

Standard culture of five bacterial strains namely, Pseudomonas aeruginosa, Escherichia coli, Salmonella typhi, Staphylococcus aureus and Klebshella pneumonia; two fungi strains namely, Fusarium oxysporium and Aspergillus niger were obtained from Ethiopian Public Health Research Institute, Addis Ababa, Ethiopia. Muller Hinton agar medium was prepared and the bacterial test organism grown at $37^{\circ} \mathrm{C}$ for $24 \mathrm{~h}$. About $38 \mathrm{~g}$ of Muller Hinton Agar was dissolved in $1000 \mathrm{~mL}$ distilled water. Then, the solution was autoclaved under $121^{\circ} \mathrm{C}$ for $15 \mathrm{~min}$. According to Andrews [6], the standard 0.5 McFarland was prepared

${ }^{*}$ Corresponding author: Besufekad SY, Department of Biotechnology, College of Natural and Computational Science, Wolkite University, Ethiopia, Tel: 251 910064185; E-mail: yohanbesufekad@gmail.com

Received October 17, 2017; Accepted November 04, 2017; Published November 11, 2017

Citation: Besufekad SY, Mekdes M, Abebech M, Delesa D, Tekalign D, et al. (2017) The Antimicrobial Activity of Leaf Extracts of Myrtus communis. J Microb Biochem Technol 9:290-292. doi: 10.4172/1948-5948.1000380

Copyright: (c) 2017 Besufekad SY, et al. This is an open-access article distributed under the terms of the Creative Commons Attribution License, which permits unrestricted use, distribution, and reproduction in any medium, provided the original author and source are credited. 
in saline solution. About $39 \mathrm{~g}$ of Potato dextrose Agar was dissolved in $1000 \mathrm{~mL}$ of distilled water for the growth of fungi strains.

\section{Preparation of extracts}

Different solvents including: n-hexane, methanol, chloroform, ethanol and petroleum ether were used to extract the essential oil of the leaf. About $250 \mathrm{~mL}$ of each solvent was measured and placed in distillation flask to extract the essential oil components sequentially. Then, the extracts of n-hexane, methanol, and chloroform based on polarity selected then dry out in open air and used for sensitivity test [7].

\section{Evaluation of antimicrobial assay}

A total seven strains among which five of them are bacteria namely, one gram positive bacterial strain Staphylococcus aureus (ATCC 25923) and four gram negative bacterial strains namely, Escherichia coli (ATCC 25922), Pseudomonas aeruginosa (ATCC 27853), Salmonella typhi and Klebsiella pneumoniae (ATCC 27736) and two of them are fungi namely Fusarium oxysporium and Asparegillus niger were involved the susceptibility test. The agar disc diffusion method was used to determine the antibacterial activity against the essential oil extracts of methanol, $\mathrm{n}$-hexane and chloroform [8]. These strains maintained in suspension media at $4^{\circ} \mathrm{C}$ and fresh inoculums were taken from the media for test antimicrobial activities.

About $6 \mathrm{~mm}$ diameter filter paper disc prepared, then $50 \mathrm{mg} / \mathrm{mL}$ concentration of each plant extract prepared and impregnated with $20 \mu \mathrm{L}$ extract of chloroform, $\mathrm{n}$-hexane, methanol and aqueous crude respectively. Then, the impregnated paper discs was dried at $40^{\circ} \mathrm{C}$ for 30 min was then placed on Muller-Hinton agar plates inoculated with the inoculum of bacteria strain such as Escherichia coli, Pseudomonas aeruginosa, Salmonella typhi, Klebsella pneumonia and Staphylococcus aureus and fungi strains including Fusarium oxysporium and Asparegillus niger inoculated in the potato dextrose agar plates. The positive controls were chloramphenicol $(20 \mu \mathrm{g} / \mathrm{mL})$ and a negative control was distilled water. Then, plates were kept under laminar flow hood for $30 \mathrm{~min}$ then, incubated at $37^{\circ} \mathrm{C}$ for $24 \mathrm{~h}$. The plates were inoculated at $37^{\circ} \mathrm{C}$ for $48 \mathrm{~h}$ and zone of inhibition was examined. The formation of clear inhibition zone around the wells about $\geq 2 \mathrm{~mm}$ diameters were taken as significant susceptibility measurement.

\section{Determination of minimum inhibitory concentration (MIC)}

The minimum inhibitory concentration is the lowest concentration of the extract to inhibit the growth of tested microorganism. This test was performed with one commonly used method which is agar well diffusion method. Double serial dilution was employed from $50 \mathrm{mg} /$ $\mathrm{mL}$ to obtain $1: 4,1: 8$ and $1: 16$ and bring $12.5 \mathrm{mg} / \mathrm{mL}, 6.25 \mathrm{mg} / \mathrm{mL}$ and $3.125 \mathrm{mg} / \mathrm{mL}$, respectively in distilled water and $25 \mu \mathrm{L}$ of diluted extract was added to prepared disc on Muller-Hinton agar as it was done for sensitivity test followed by identifying MIC concentration. The antibiotics chloramphenicol was used as a positive control. After $24 \mathrm{~h}$ incubation time the inhibition zone of the specific extract was measured.

\section{Statistical Analysis}

The experimental study was laid down in completely randomized design with three replication. The mean value and standard deviation value was used for analysis using SPSS 20 statistical software package.

\section{Results and Discussion}

The results obtained in the present study revealed that tested Myrtus communis essential oil possess potential antibacterial activity and antifungi activity against some selected bacterial strains indicated on Tables 1 and 2 respectively.

The antimicrobial activity of Myrtus communis is influenced predominantly by either type of bacterial or fungi strain and extraction solvent. Among all the extracts $n$-hexane and methanolic extracts indicated maximum antibacterial activity against $E$. coli with mean of zone of inhibition $5.67 \mathrm{~mm}$. This may be due to the ability of n-hexane and methanol to extract some semi polar dissolved component of plants that have active properties. The test results were compared with standard antibiotics chloramphenicol $(15 \mu \mathrm{g} / \mathrm{mL})$ which was much lower zone of inhibition than the extract.

Previously, Majhenic et al. reported methanol and ethanol possessed better antimicrobial activity of medicinal plants. Therefore, the results indicated in this study are supported by previous studies [8]. The highest antibacterial action of solvent including methanol among polar solvent and n-hexane from non-polar solvent extract against bacterial strain may be due to the ability of the solvent to extract some semi polar and non-polar dissolved component of plants that have active properties. Therefore, Myrtus communis essential oil extract has antibacterial activity may be related to their ability to inactivate cell envelope transport proteins, enzymes, microbial adhesions, and may form complex with polysaccharides [9]. In addition, Negero et al. reported the antimicrobial activity of the formulation of Eugenia caryophyllata L. "Krunfud" and Myritus communis L [10].

\begin{tabular}{|c|c|c|c|c|c|}
\hline \multirow[b]{2}{*}{ Test organism } & \multicolumn{3}{|c|}{ Inhibition zone (mm) } & \multirow{2}{*}{$\begin{array}{c}\text { Mean+S.D } \\
\text { Chloroform Extract }\end{array}$} & \multirow{2}{*}{$\begin{array}{c}\text { Control } \\
\text { Chloramphenicol }\end{array}$} \\
\hline & Water Extract & $\mathrm{N}$-Hexane Extract & Methanol Extract & & \\
\hline Escherichia coli (ATCC 25922) & 0 & $5.67 \pm 3.35$ & $5.67 \pm 4.35$ & $3.17 \pm 1.04$ & $3 \pm 2.29$ \\
\hline Salmonela typhi (ATCC19430) & 0 & $4 \pm 1.32$ & $4 \pm 0.5$ & $4 \pm 0.86$ & $3 \pm 0.5$ \\
\hline Staphylococcus aureus (ATCC 25923) & 0 & $5.5 \pm 3.46$ & $1 \pm 0.5$ & $2.2 \pm 2.46$ & $4.5 \pm 2.18$ \\
\hline Pseudomonas aeruginosa (ATCC 27853) & 0 & $2.66 \pm 1.53$ & $3.77 \pm 2.75$ & $1.5 \pm 0.86$ & $9 \pm 2.78$ \\
\hline
\end{tabular}

*Statistically significant: $\mathrm{P}<0.05$; (One way ANOVA)

Table 1: Means of inhibition growth diameter obtained by essential oil of Myrtus communis on selected stains of bacterial strains

\begin{tabular}{|c|c|c|c|c|c|}
\hline Inhibition zone (mm) & & Mean+S.D & & & \\
\hline Test organism & Water Extract & N-Hexane Extract & Methanol Extract & Chloroform Extract & Chloramphenicol \\
\hline Asparagillus nigrum (ATCC11414) & 0 & $4.83 \pm 3.54$ & $4.75 \pm 1.98$ & $11.83 \pm 5.85$ & $22.66 \pm 4.25$ \\
\hline Fusarium oxysporium (ATCC 20328) & 0 & $11.33 \pm 10.69$ & $7 \pm 6.39$ & $15.16 \pm 11.72$ & $10.66 \pm 4.72$ \\
\hline
\end{tabular}

*Statistically significant: $\mathrm{P}<0.05$; (One way ANOVA)

Table 2: Means of inhibition zone diameter obtained by essential oils Myrtus communis is on selected fungi species 
The effectiveness of essential oil was evaluated on both (Aspergillus niger and Fusarium oxysporium). The ANOVA analysis indicated that chloroform is the quite best solvent to extract the oil from Myrtus communis against this fungus than the other solvent as indicated in the Table 2. The result showed that chloroform has showed maximum inhibition zone $(15.16 \mathrm{~mm})$ and minimum zone of inhibition obtained from methanol extract on $A$. niger. However, the positive control has large value of inhibition zone than chloroform extract. This may due to the response of antifungal activity need polar and other essential compounds. However, n-hexane has better zone of inhibition than other solvents with zone of inhibition value $11.33 \mathrm{~mm}$ against Fusarium oxysporium and better than the control used [11].

Therefore, minimum inhibitory concentration (MIC) of essential oil evaluated for $\mathrm{n}$-hexane against bacterial strains including three gram positive (Staphylococcus aureus, Salmonella typhi), two gram negative (E. coli and Pseudomonas aeruginosa) bacteria and two fungi (Aspergillus niger and Fusarium oxysporium). These strains used in this study are pathogenic or toxigenic to humans or to plants.

The Minimum inhibition value against $E$. coli strain and $P$. aeruginosa strain of the N-Hexane extract at the concentration of $12.5 \%$ has the largest mean value $(1.33-1.66 \mathrm{~mm})$ respectively, it indicates that when the concentration of $\mathrm{n}$-hexane is large the inhibition zone of $E$. coli and $P$. aeruginosa is large (Table 3). Hence, to inhibit $E$. coli and P. aeruginosa appropriately the large concentration of $n$-hexane solvent should be required.

The minimum inhibition value against $S$. typhi strain and S. aureus strain of n-hexane extract at the concentration of $3.125 \%$ has the largest mean $(1.83-1.66 \mathrm{~mm})$ respectively, it indicates that when the concentration of $\mathrm{n}$-hexane is low, the inhibition zone of S. typhi and $S$. aureus is large. Hence, the small concentration of n-hexane solvent is required for S. typhi and S. aureus inhibition.

The minimum inhibition concentration of chloroform extract for A. niger and F. oxysporium inhibitions was at the medium concentration that is $6.25 \%$; it indicates that when the moderate concentration of chloroform used to extract the oil from Myrtus communis it is most appropriately inhibit the growth of fungi than at the high concentration and the low concentration.

Whatever the extraction solvent is differing; the essential oil of leaves of Myrtus communis could inhibit the growth of bacteria and fungi. Thus, they present a broad spectrum of antimicrobial activity. Finally note that many studies have focused on the fact that essential oil had more impact on gram-negative ones [12]. This resistance is due to the fact that gram-negative bacteria have a wall associated with an outer complex membrane although poor in peptidoglycan. This slow down the passage of essential oil hydrophobic compounds (Table 4).

\begin{tabular}{|c|c|c|}
\hline Test organism & Gram type & Concentration $(\mathrm{mg} / \mathrm{ml})$ \\
\hline Escherichia coli (ATCC 25922) & \multirow{2}{*}{$-v e$} & \multirow{2}{*}{3.125} \\
\hline Pseudomonas aeruginosa (ATCC 27853) & & \\
\hline Salmonela typhi (ATCC 19430) & $-v e$ & \multirow{2}{*}{12.5} \\
\hline Staphylococcus aureus (ATCC25923) & $+\mathrm{ve}$ & \\
\hline
\end{tabular}

*-ve Gram Negative, +ve Gram Positive

Table 3: Minimum inhibition value against bacterial strain of the $n-H e x a n e$ extract of Myrtus communis.

\begin{tabular}{|l|c|}
\hline \multicolumn{1}{|c|}{ Test organism } & Concentration (mg/mL) \\
\hline Asparagillus niger (ATCC11414) & 6.25 \\
\hline Fusarium oxysporium (ATCC 20328) & \\
\hline
\end{tabular}

Table 4: Minimum inhibition value against fungi stains of chloroform extract of Myrtus communis.
The result of ANOVA analysis indicates that the two solvents such as $n$-hexane and methanol have the large value of mean $(5.67 \mathrm{~mm})$ than other solvents. It indicates that these solvents are the best solvent for Myrtus communis dissolving for resisting E. coli than other solvent as shown in the Table 1. On other hand, Staphylococcus aureus n-hexane solvent has the greatest mean $(5.5 \mathrm{~mm})$ than the other solvent to extract the essential oil for inhibit the growth of $S$. aureus. To inhibit the growth of $P$. aeruginosa methanol is the most solvent to dissolve the Myrtus communis leaf with the range value of $3.77 \mathrm{~mm}$ than the other solvent.

\section{Conclusion}

The result of different extracts against bacterial and fungi strains suggested that $\mathrm{n}$-hexane and methanolic extract can be used for treatment of infection caused by E. coli and Staphylococcus aureus. The essential extract of chloroform can be used for treatment of infection caused by Fusarium oxysporium. The result clearly elaborated that Myrtus communis has great potential to invade some human pathogenic bacteria and fungi as it showed strong inhibition against E. coli and Staphylococcus aureus with n-hexane, methanol and chloroform extract inhibition on Fusarium oxysporium. The problem of microbial resistance is growing and the outlook of the use of antimicrobial drugs in future is uncertain. Therefore, the study also indicated that bacteria and fungi able to be controlled by extracts of medicinal plants. Generally, the plant will have a role of both antibacterial and anti-fungal activity; hence its needs further experiment. Some of these observations have helped in identifying the active principle responsible for such activities and in the developing drugs for the therapeutic use in human beings.

\section{Acknowledgment}

The authors would like to acknowledge Wolkite University for facilitating the research work. We are also deeply grateful to staff of department of biotechnology

\section{References}

1. Asfaw Z, Wondimu T (2007) Introduction to ethnobiology: People and the biota Addis Ababa: Addis Ababa University Press.

2. Diaz AM, Abeger A (1987) Myrtus communis: Composicionquimica actividadbiologica de susextractos una revision. Fitoterapia 58: 167-174.

3. Getahun A (1974) Some common medicinal and poisonous plants used in ethiopia folk medicine. Ethiopia: Addis Ababa University.

4. Gemeda N, Kelbessa U, Ashenif T, Hirut L, Daniel M, et al. (1998) Antimicrobia activity of topical formulation containing Eugenia caryophyllata L. (Krunfud) and Myritus communis L. (Ades) essential oils on selected skin disease causing microorganisms. Ethiop J Health Sci 18: 101-107.

5. Bhasin P, Bansal D, Punia A, Sehrawat A (2012) Antimicrobial activities of Lepidiumsativum: Medicinal plant used in folklore remedies in India. J Pharm Res 3: 1643-1645

6. Andrews M (2006) Determination of minimum inhibitory concentrations Chapter two. Department of Microbiology, city Hospital NHS Trust: 1-19.

7. Taye B, Giday M, Animut A, Seid J (2011) Antibacterial activities of selected medicinal plants in traditional treatment of human wounds in Ethiopia. Asian Pac J Trop Biomed 1: 370-375.

8. Majhenic L, Kerget MS, Knez Z (2007) Antioxidant and antimicrobial of guarana seed extracts. Food Chem 104:1258-1268.

9. Ya C, Gaffney S, Lilley T, Haslam E (1998) Carbohydrate polypheno complexation. In: Chemistry and significance of condensed tannins, 552-553.

10. Negero G, Walelegn M, Hirut L, Ashenafi T, Urgesa K, et al. (2014) Insecticidal activity of some traditionally used Ethiopian medicinal plants against sheep ked melophagusovinus. J Paras Res.

11. Kokoska L, Polesny Z, Rada V, Nepovim A, vanek, T (2002) Screening of some Siberian medicinal plants for antimicrobial activity. J Etnho Pharmacol. 82: 51-53.

12. Deuel HJ (1951) The lipids, their chemistry and biochemistry. Interscience Publishers 1: 53-57. 